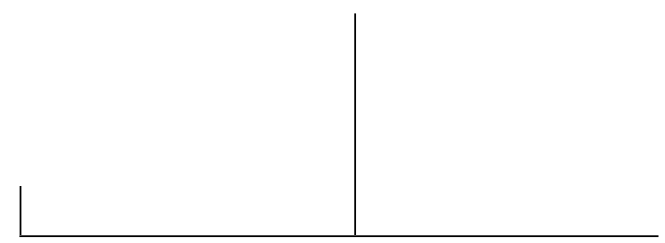

Rev. Latinoam. Psicopat. Fund., São Paulo, v. 15, n. 4, 868-880, dezembro 2012

\title{
A questão do fundamento em Freud: elementos para uma psicanálise aplicada*
}

\author{
Vinicius Anciães Darriba \\ Angela Cristina da Silva
}

\begin{abstract}
Dentre as muitas reflexões que suscitam o debate sobre a inserção da psicanálise e dos psicanalistas no domínio da saúde mental, interroga-se aqui o valor de orientação que pode ter o que Freud entende quanto à questão dos fundamentos no que diz respeito ao campo da psicanálise. Para tal, enfocam-se as passagens da obra em que o autor discute tal questão, seja no âmbito dos escritos metapsicológicos, técnicos ou daqueles em que tece considerações acerca das possibilidades da psicanálise aplicada, incluída a própria aplicação à terapêutica.
\end{abstract}

Palavras-chave: Freud, psicanálise aplicada, fundamento, terapêutica

* Artigo referente a resultado parcial de pesquisa realizada no Mestrado em Psicologia, Linha de Pesquisa de Psicologia Clínica, da Universidade Federal do Paraná (Curitiba, PR, Br), com auxílio de bolsa concedida pela Capes - Coordenação de Aperfeiçoamento de Pessoal de Nível Superior (Brasília, DF, Br). 
Em 1917, na conferência intitulada Psicanálise e Psiquiatria (1917/1996), ao traçar um paralelo entre as duas disciplinas, Freud utiliza-se de um exemplo clínico para enfatizar as limitações da medicina diante da neurose. Considerando as possibilidades que, em compensação a tais limitações, se apresentam à psicanálise, ele afirma que, ainda que a psicanálise tenha melhores destinos a dar para aquele que chega até ela movido por um tipo especial de sofrimento, isso só acontece porque este campo, à medida que se estruturou, continuou em um persistente movimento de mudanças, quando estas se fizeram necessárias. Apesar disso, Freud (1996/1917[1916]) afirma que há algo dela que permanece imutável:

[...] não me impedirei de modificar ou retirar qualquer uma das minhas teorias sempre que a progressão da experiência possa exigi1o. Com referência a descobertas fundamentais, até o momento atual, nada tenho a modificar, e espero que isto venha a manter-se verdadeiro no futuro. (p. 292)

Salta aos olhos o que Freud chama de "descobertas fundamentais". Ao mesmo tempo, parece impossível não questionar por que, afinal, o autor considera terem algumas de suas descobertas o estatuto de fundamento para a psicanálise. Também somos levados a pensar que descobertas seriam estas a que o autor se refere. Este artigo se guia por estas perguntas. A elas chegamos questionando-nos como aquilo que Freud toma por fundamento pode nos orientar quando pensamos nas possibilidades e impossibilidades da psicanálise aplicada. Questionamento que entendemos necessário em face, por exemplo, da consolidada inserção da psicanálise e dos psicanalistas no domínio que se designa como o da saúde mental. Dentre os muitos caminhos que assume o debate sobre tal inserção, a pergunta que aqui colocamos é que valor de orientação pode ter aí 
aquilo que Freud, ao passo mesmo em que abria um campo, encaminhou acerca de seus fundamentos.

O primeiro elemento a ser levado em conta, portanto, é que, para Freud, a psicanálise tem seus fundamentos. Tanto que a desconsideração ou não aceitação destes levou, como sabemos, a dissidências entre ele e alguns de seus colaboradores, relato feito com pormenores em "A história do movimento psicanalítico" (1996/1914). Mais de quinze anos depois deste artigo, escrito logo depois de ocorridas as secessões, Freud (1996/1933) retoma a necessidade de a psicanálise ser tomada como unidade em uma conferência, reiterando a impossibilidade daquele que fala em nome dela abrir mão do que se estruturou como conceitos fundamentais. Isto porque entendia que muitos dos que afirmam usar a psicanálise em sua prática não a admitem como um todo, ao que adverte: "embora a estrutura da psicanálise esteja inacabada, ela apresenta [...] uma unidade da qual elementos componentes não podem ser separados ao capricho de qualquer um" (p. 137).

Neste mesmo texto, é preciso também evidenciar outras duas passagens que fazem eco à anterior. Na primeira, Freud afirma existirem " [...] pessoas que admitem a validade de determinadas partes da análise, [...] mas que, por outro lado, rejeitam outras partes dela [...]" (idem). Na segunda, ele assevera: "A atividade psicanalítica é árdua e exigente; não pode ser manejada como um par de óculos que se põe para ler e se tira para sair para caminhar. Via de regra, a psicanálise possui um médico inteiramente, ou não o possui em absoluto" (p. 150).

Os três excertos da obra freudiana apoiam o argumento de que existem, na psicanálise, peças que a autenticam. Em "A história do movimento psicanalítico" (1996/1914), além de tratar dos fatos referentes às dissidências, Freud também discorreu sobre estes fundamentos, hipóteses e descobertas dos quais parte a psicanálise, realinhando este campo a partir de uma perspectiva que possibilita a apreensão do que ele considerava essencial para a existência da psicanálise. Assim, demonstra as razões por que as teorias construídas e defendidas pelos dissidentes não deveriam ser consideradas correlatas. Freud ampara-se na história da psicanálise para situar a diferença entre o que seria a psicanálise e o que seus antigos colaboradores propunham. A partir da história, mostra que tais dissidências ocorreram porque esbarraram nos desdobramentos do que Freud toma por pedra angular da psicanálise:

A teoria da repressão é a pedra angular sobre a qual repousa toda a estrutura da psicanálise. É a parte mais essencial e, todavia, nada mais é senão a formulação teórica de um fenômeno que pode ser observado quantas vezes se desejar se se empreende a análise de um neurótico sem se recorrer à hipnose. (p. 26) 
Através deste artigo, podemos ver que a sustentação da psicanálise assume em Freud a conotação de luta pela verdade. Nele, o autor defende pontos que não gostaria que fossem tomados como premissas das quais a psicanálise parte, mas como descobertas que a psicanálise fez (p. 26). Se essa defesa foi necessária, é porque as já mencionadas dissidências sacrificaram parte de tais descobertas em troca de aceitação e reconhecimento externos, abdicando, assim, do que, para Freud, tem valor de verdade. Sobre tais descobertas, o autor afirma:

[...] a teoria da psicanálise é uma tentativa de explicar dois fatos surpreendentes e inesperados que se observam sempre que se tenta remontar os sintomas de um neurótico a suas fontes no passado: a transferência e a resistência. Qualquer linha de investigação que reconheça esses dois fatos e os tome como ponto de partida de seu trabalho tem o direito de chamar-se psicanálise, mesmo que chegue a resultados diferentes dos meus. (idem)

Salienta ainda:

Entre os outros novos fatores que foram acrescentados ao processo catártico como resultado de meu trabalho e que o transformou em psicanálise, posso mencionar em particular a teoria da repressão e da resistência, o reconhecimento da sexualidade infantil e a interpretação e exploração de sonhos como fonte de conhecimento do inconsciente. (p. 25)

Anos mais tarde, em "Dois verbetes de enciclopédia” (1996/1923[1922]), aponta:

A pressuposição de existirem processos mentais inconscientes, o reconhecimento da teoria da resistência e repressão, a apreciação da importância da sexualidade e do complexo de Édipo constituem o principal tema da psicanálise e os fundamentos de sua teoria. (p. 264)

Recorremos a estas citações por demonstrarem pequenas as variações em torno das quais estariam os fundamentos da psicanálise, estes se apresentando reiteradamente entrelaçados nos textos de Freud. Foi seu trabalho teórico ininterrupto, em associação com a prática clínica e com a intitulada autoanálise que cunharam esta conviç̧ão. Convicção que foi descrita, por Freud, como algo que se impôs a ele. Na própria "História do movimento psicanalítico", confessou que, estando a ponto de desistir do trabalho quando a hipótese da sedução infantil na histeria desmoronou, "talvez tenha perseverado apenas porque já não tinha outra escolha" (Freud, 1996/1914, p. 27).

Que seu trabalho tenha sido assim vivido é o que possibilita a Freud (1996/ 1917[1916]) afirmar: "Não desejo suscitar convicção; desejo estimular o pensamento e derrubar preconceitos" (p. 289). Ao que segue aconselhando: "Deveriam ouvir atentamente e permitir que atue nos senhores aquilo que lhes digo" (idem). 
Vemos o autor implicado nas concepções que estabelece à medida que a psicanálise avança como prática clínica, teoria e método de investigação. Vemos situações em que, ainda que a ponto de desistir, percebe-se impossibilitado de fazê-lo.

Mesmo nos textos voltados ao público leigo, Freud se preocupa em refazer o caminho da fundamentação teórica; buscando evitar desvios e conclusões equivocadas e desmistificar o que se falava sobre a psicanálise à luz, justamente, da incompreensão de seus fundamentos. Esforça-se por evitar más interpretações da psicanálise, como quando, em "Psicanálise silvestre" (1910a/1996), esclarece questões referentes a determinadas proposições psicanalíticas.

Nesse artigo, reafirma o papel do fator sexual enquanto imprescindível à psicanálise. Esta compreensão, no entanto, ultrapassa a literalidade do sexual para o senso comum, o que pode levar a erros, como na situação examinada no artigo, em que se acredita que o sofrimento do paciente é decorrente de uma ignorância que pode ser eliminada pela informação. Quanto a isso, Freud (1996/1910a) contrapõe: "o fator patológico não é esse ignorar propriamente, mas estar o fundamento dessa ignorância em suas resistências internas [...]" (p. 237). As resistências preservam a ignorância, mas a informação racionalizada não fornece os pressupostos necessários para a compreensão. Com respeito aos fundamentos da psicanálise, a convicção não pode ser, então, suscitada. É no decurso do que designamos como experiência analítica que ela se impõe, como Freud verifica.

Além de resguardar e esquadrinhar os conceitos e hipóteses fundamentais, Freud discorreu sobre a importância que adquiriu e que ainda poderia vir a adquirir à ampliação deste campo, com a condição de que fossem mantidos firmes os alicerces que o estruturam. É preciso apontar, então, que, ao mesmo tempo em que ratifica ter a psicanálise seus fundamentos, Freud (1996/1914) especula acerca das possibilidades de ampliação do campo. Ele afirma não estar atrelado aos limites que alguns poderiam dar à psicanálise, identificando "[...] material de trabalho para uma geração de pesquisadores" e acrescentando: "não duvido de que será realizado tão logo as resistências contra a psicanálise sejam superadas em seu campo de origem" (p. 47).

\section{O que é fundamental e o que pode ser modificado}

Ao identificarmos em Freud os votos de que o campo da psicanálise se amplie, prevendo para ela possibilidades de aplicação por vir, é importante ter em conta que, embora como visto, ele sustente a preservação de seus fundamentos, em muitos outros momentos de sua obra enfatiza a abertura a modificações. Ele defende a importância de novas observações e de eventuais mudanças, tanto na 


\section{SAÚDE MENTAL}

teoria quanto na técnica, desde que se mantenham firmes aqueles conceitos que ele situa enquanto fundamentais. A importância atribuída por Freud à questão do fundamento não pode ser confundida, então, com ortodoxia ou arbitrariedade. É o que vemos em seus artigos sobre a técnica. Para evidenciar a posição de Freud (1996/1912), recorremos a um trecho situado na introdução de um destes artigos:

As regras técnicas que estou apresentando aqui alcancei-as por minha própria experiência [...]. Ver-se-á facilmente que elas (ou, pelo menos, muitas delas) podem ser resumidas num preceito único. [...] Devo, contudo, tornar claro que o que estou asseverando é que esta técnica é a única apropriada à minha individualidade; não me arrisco a negar que um médico constituído de modo inteiramente diferente possa ver-se levado a adotar atitude diferente em relação a seus pacientes e à tarefa que se lhe apresenta. (p. 125)

Este preâmbulo permite vislumbrar que psicanalisar - e produzir conhecimento neste campo - está condicionado ao singular de cada um que, a partir da psicanálise, desprendeu-se de um saber conclusivo. Por outro lado, Freud faz referência a um preceito único que, ao longo do texto, elucida tratar-se da livre associação. Obviamente, a livre associação como preceito único não significa que se faz psicanálise sempre que se deixa o interlocutor falar livremente. Ao referir-se à livre associação neste texto, Freud está preocupado com o que é preciso, do lado do analista, para a sua sustentação. Neste sentido, observa, com relação às distintas recomendações que apresenta, que "todas elas se destinam a criar, para o médico, uma contrapartida à "regra fundamental da psicanálise"” (p. 130). Não por acaso é este um dos escritos em que Freud ressalta a importância da experiência analisante para a prática da psicanálise.

A questão do que é a psicanálise fica atrelada, assim, à questão do que é um psicanalista. Em outro escrito onde isto é retomado, "Análise terminável e interminável" (1937/1996), a divisa da verdade reaparece reportada a este atravessamento da experiência da análise: “[...] o relacionamento analítico se baseia no amor à verdade - isto é, no reconhecimento da realidade - e que inclui qualquer tipo de impostura ou engano" (p. 265). Ainda em outro trabalho, havia indicado: "A psicanálise já encerra em si mesma fatores revolucionários suficientes para garantir que todo aquele que nela se educou jamais tomará em sua vida posterior o partido da reação e da repressão" (Freud, 1996/1933, p. 149).

Se, de um lado, Freud preconiza a preservação dos fundamentos e, de outro, sustenta a abertura a novas descobertas e modificações - no interesse da ampliação do campo - depreendemos de seu texto que a conexão entre estas duas orientações passa pelo que constitui a posição do analista. Vale notar ainda que, em sua obra, a defesa implacável dos fundamentos da psicanálise se faz nos 
termos dos elementos metapsicológicos, ao passo que as indicações de que não se trata de impor regras e de que a variabilidade seria própria ao fazer psicanalítico predominam nas discussões técnicas.

Talvez por isso, quando investiga a incidência, no terreno da ética, da experiência inaugurada por Freud, Lacan (1991/1959-1960) observa: "Pois bem, se aproximamos de tão perto, este ano, a evolução da metapsicologia freudiana é porque podemos aí encontrar o rastro de uma elaboração que reflete um pensamento ético" (p. 51). A metapsicologia de Freud traduziria, assim, não estritamente um rigor teórico, mas uma orientação para a sustentação de um campo. Traduziria o esforço de Freud em transmitir, desde seu caso mesmo, o que fundamenta a experiência analítica. Fundamento teria aqui o sentido mesmo do que funda um campo. É, então, por seu valor de transmissão, que Lacan acrescenta em relação à metapsicologia freudiana:

Esta se encontra no centro de nosso trabalho, quaisquer que sejam as dificuldades das quais teremos, talvez, de tomar consciência, e é ela que mantém coeso todo esse mundo que a comunidade analítica representa, dispersão - que frequentemente dá a impressão de espalhamento - de uma intuição fundamental que é, por cada um, retomada sob um de seus aspectos. (p. 51)

O que Freud (1996/1910b) reitera tratar-se de descobertas, e não de premissas, advém da exploração do campo do inconsciente tornada possível por meio do dispositivo analítico. Daí ele afirmar que o psicanalista é aquele que "se distingue pela rigorosa fé no determinismo da vida mental" (p. 36). Novamente a indicação de uma convicção que, seguidamente em sua obra, Freud assenta na experiência da análise. A ideia de uma convicção, e a correlata referência a um compromisso com a verdade, não são diretamente reportáveis ao ideal de ciência que também o move. Não por acaso, o preceito único que vimos, segundo Freud, dever orientar o analista implica certa suspensão do saber, determina para o analista uma relação não ordinária ao saber.

\section{Psicanálise aplicada}

À medida que a orientação de Freud com respeito ao que é fundamento na psicanálise revela-se cara a ele, é de supor que, nos textos em que trata das aplicações da psicanálise, esta compareceria. Não se trata tanto, nestes textos, do autor ajuizar se as aplicações da psicanálise promovidas por outrem preservariam ou não seus fundamentos, decidindo o que pode ou não ser chamado de psicanálise. Embora faça isso em alguns momentos, predominantemente vemos o próprio Freud se ocupando das aplicações da psicanálise, interessado na ampliação 
e no aprofundamento deste campo. Efetivamente, como sabemos, foi ele quem introduziu a psicanálise em diversos outros terrenos, sustentando que "as aplicações da psicanálise são, também, sempre confirmações dela" (Freud, 1996/1933, p. 146).

Se, por um lado, o otimismo de Freud (1996/1914) é patente em comentários como: "Afora isso, tudo está ainda aguardando trabalhadores, que podem esperar uma colheita particularmente rica neste campo" (p. 45); por outro lado, ele alerta que a extensão da psicanálise para além do tratamento das neuroses associa-se grande parte da rejeição por ela sofrida (p. 44). A rejeição à psicanálise, aliás, já se configurou, para Freud, como uma aplicação da psicanálise, uma das primeiras como ele mesmo atesta: "uma das primeiras aplicações da psicanálise consistiu em nos ensinar a compreender a oposição que nossos contemporâneos nos movem pelo fato de exercermos a psicanálise" (Freud, 1996/1933, p. 143). No caso, o autor recorreu ao conceito clínico de resistência para compreender também a resistência à psicanálise, entendendo-a como a própria resistência ao inconsciente. Tal interpretação de Freud implica, vale dizer, que tal resistência não pode ser tomada como exclusividade de seus opositores. Ao contrário, pode igualmente incidir junto àqueles que falam em seu nome, questão crucial quando nos interrogamos sobre a questão da psicanálise aplicada.

No exemplo acima, como em muitos outros na obra de Freud, ele parte de um saber advindo da clínica psicanalítica. A ideia de aplicação da psicanálise pode, então, situar a demarcação em relação a um terreno de origem, que seria o de um saber que se estruturou a partir do trabalho clínico com a neurose, como observa abaixo:

Disse-lhes que a psicanálise começou como um método de tratamento, mas não quis recomendá-lo ao interesse dos senhores como método de tratamento e sim por causa das verdades que ela contém, por causa das informações que nos dá a respeito daquilo que mais interessa aos seres humanos - sua própria natureza - e por causa das conexões que ela desvenda com as mais diversas atividades. Como método de tratamento, é um método entre muitos, embora seja, para dizer a verdade, primus inter pares. Se não tivesse valor terapêutico, não teria sido descoberto, como o foi, em relação a pessoas doentes, e não teria continuado desenvolvendo-se por mais de trinta anos. (Freud 1996/1933, p. 154)

Nesta observação, Freud reitera o papel preponderante da psicanálise enquanto método de tratamento e o valor terapêutico que possui. No entanto, declara que o alcance das verdades a que ela chega ultrapassa este âmbito. $O$ fato de que a psicanálise tenha começado como método de tratamento, como afirma o autor, não impede, então, que a própria terapêutica acabe por se distinguir como uma aplicação da psicanálise. A aplicação à terapêutica poderia figurar, portanto, como uma das aplicações a que ele se reporta:

Rev. Latinoam. Psicopat. Fund., São Paulo, v. 15, n. 4, p. 868-880, dezembro 2012 
Nosso primeiro objetivo, naturalmente, foi o de compreender os distúrbios da mente humana [...]. Depois, no entanto, percebemos as estreitas relações, a própria identidade interna entre processos patológicos e aquilo que se conhece como processos normais. A psicanálise tornou-se psicologia profunda; e uma vez que nada daquilo que o homem cria ou faz é compreensível sem a cooperação da psicologia, as aplicações da psicanálise a numerosas áreas do conhecimento [...] entraram em cena e requereram debate. (p. 145)

A ideia de que a própria terapêutica já se configuraria, para Freud (1990/ 1933[1932]), como uma aplicação da psicanálise, confirma-se em discussões nas quais ele se propõe a dizer "algumas palavras a respeito da psicanálise como forma de terapia" (p. 185) ou a debater "a aplicação da análise ao tratamento de pacientes" (Freud, 1990/1926, p. 288). Caberia, então, para os fins deste artigo, examinar as considerações do autor nos momentos de sua obra em que se detém sobre as possibilidades de aplicação da psicanálise neste terreno, tomando-o como um terreno estendido por relação ao dispositivo do qual advieram as descobertas de Freud.

Ao abrir o campo da psicanálise a pesquisas que se interessem por outras áreas, Freud inclui, então, a extensão da terapêutica psicanalítica a contextos públicos e em larga escala, especificando as condições para tal em "Linhas de progresso na terapia psicanalítica" (1996/1919[1918]):

No entanto, qualquer que seja a forma que essa psicoterapia para o povo possa assumir, quaisquer que sejam os elementos dos quais se componha, os seus ingredientes mais efetivos e mais importantes continuarão a ser, certamente, aqueles tomados à psicanálise estrita e não tendenciosa. (p. 181)

Ao afirmar que os principais ingredientes para uma psicanálise aplicada devem ser obtidos no que chama de psicanálise estrita, encontramos a mesma orientação a que vimos o autor chegar quando se pergunta sobre a possibilidade do praticante aceder aos fundamentos deste campo e preservá-los. Isto é, aqui também Freud assenta a efetividade da psicanálise em uma ordem de convicção que é indissociável da experiência analítica. Neste sentido, em um texto que tem justamente por título As perspectivas futuras da terapêutica psicanalítica (1996/ 1910c), ele observa:

[...] nenhum psicanalista avança além do quanto permitem seus próprios complexos e resistências internas; e, em consequência, requeremos que ele deva iniciar sua atividade por uma autoanálise e levá-la, de modo contínuo, cada vez mais profundamente, enquanto esteja realizando suas observações sobre seus pacientes. (p. 150)

Quando, a estas observações, associamos a afirmação de Freud de que a psicanálise nasceu a partir de um método de pesquisa que culminou em um

Rev. Latinoam. Psicopat. Fund., São Paulo, v. 15, n. 4, p. 868-880, dezembro 2012 
método de tratamento cujos alicerces revelam estruturar-se na própria pesquisa (Freud, 1996/1913[1911], p. 225), podemos entender que tomar as aplicações da psicanálise como campo de pesquisa é homólogo ao que funda a experiência analítica em seu sentido estrito. Na discussão empreendida acerca das possibilidades da psicanálise aplicada, um outro elemento é, então, retomado por Freud, além da vinculação dos fundamentos da psicanálise à própria experiência, somente através da qual aqueles se fariam acessíveis. Trata-se da dimensão da descoberta, a qual vimos o autor frisar ser a que se referem os fundamentos na psicanálise. $\mathrm{Ou}$ seja, os fundamentos da psicanálise são incidência da pesquisa, somente na qual o próprio estatuto de fundamento poderia ser verificado.

A psicanálise aplicada, inclusive no que concerne à terapêutica, configura-se como um campo de pesquisa ao qual outro é imprescindível, o da experiência analítica estrita, se quisermos manter o termo de Freud. Só aí poderíamos falar de alguma garantia quanto aos fundamentos, desde os quais a questão da psicanálise aplicada deve ser sempre tomada, se formos freudianos.

\section{Referências}

Freud, S. (1996). Psicanálise silvestre. In Edição Standard Brasileira das Obras Psicológicas Completas de Sigmund Freud (Vol. XI). Rio de Janeiro: Imago. (Trabalho original publicado em 1910a)

Freud, S. (1996). Cinco lições de psicanálise. In Edição Standard Brasileira das Obras Psicológicas Completas de Sigmund Freud (Vol. XI). Rio de Janeiro: Imago. (Trabalho original publicado em 1910b)

Freud, S. (1996). As perspectivas futuras da terapêutica psicanalítica. In Edição Standard Brasileira das Obras Psicológicas Completas de Sigmund Freud (Vol. XI). Rio de Janeiro: Imago. (Trabalho original publicado em 1910c)

Freud, S. (1996). Recomendações aos médicos que exercem a psicanálise. In Edição Standard Brasileira das Obras Psicológicas Completas de Sigmund Freud (Vol. XII). Rio de Janeiro: Imago. (Trabalho original publicado em 1912)

Freud, S. (1996). Sobre o início do tratamento (novas recomendações aos médicos que exercem a psicanálise I). In Edição Standard Brasileira das Obras Psicológicas Completas de Sigmund Freud (Vol. XII). Rio de Janeiro: Imago. (Trabalho original publicado em 1913[1911])

Freud, S. (1996). A história do movimento psicanalítico. In Edição Standard Brasileira das Obras Psicológicas Completas de Sigmund Freud (Vol. XIV). Rio de Janeiro: Imago. (Trabalho original publicado em 1914)

Freud, S. (1996). Conferência XVI. In Edição Standard Brasileira das Obras Psicoló-

Rev. Latinoam. Psicopat. Fund., São Paulo, v. 15, n. 4, p. 868-880, dezembro 2012 
gicas Completas de Sigmund Freud (Vol. XVI). Rio de Janeiro: Imago. (Trabalho original publicado em 1917[1916])

Freud, S. (1996). Linhas de progresso na terapia psicanalítica. In Edição Standard Brasileira das Obras Psicológicas Completas de Sigmund Freud (Vol. XVII). Rio de Janeiro: Imago. (Trabalho original publicado em 1919[1918])

Freud, S. (1996). Dois verbetes de enciclopédia. In Edição Standard Brasileira das Obras Psicológicas Completas de Sigmund Freud (Vol. XVIII). Rio de Janeiro: Imago. (Trabalho original publicado em 1923[1922])

Freud, S. (1996). A questão da análise leiga - conversações com uma pessoa imparcial. In Edição Standard Brasileira das Obras Psicológicas Completas de Sigmund Freud (Vol. XX). Rio de Janeiro: Imago. (Trabalho original publicado em 1926[1925])

Freud, S. (1996). Novas conferências introdutórias - Explicações, aplicações e orientações. In Edição Standard Brasileira das Obras Psicológicas Completas de Sigmund Freud (Vol. XXII). Rio de Janeiro: Imago. (Trabalho original publicado em 1933)

Freud, S. (1996). Análise terminável e interminável. In Edição Standard Brasileira das Obras Psicológicas Completas de Sigmund Freud (Vol. XXIII). Rio de Janeiro: Imago. (Trabalho original publicado em 1937)

Lacan, J. (1991). O seminário. Livro 7. A ética da psicanálise. Rio de Janeiro: Jorge Zahar. (Trabalho original publicado em 1959-1960)

\section{Resumos}

(The question of fundamentals in Freud: elements for applied psychoanalysis)

Among the many reflections brought up by the debate on the presence of psychoanalysis and psychoanalysts in the area of mental health, the author discusses the place of Freud's proposals regarding the fundamentals of the field of psychoanalysis. To this end, passages by Freud that treat this question are analyzed, including points on metapsychology, analytic technique, and in passages where Freud discusses the possibilities of the applied psychoanalysis, including even therapeutics.

Key words: Freud, applied psychoanalisys, fundamentals, therapeutics

(La question du fondement freudien: éléments pour une psychanalyse appliquée)

Parmi les multiples réflexions que suscite le débat sur l'insertion de la psychanalyse et des psychanalystes dans le domaine de la santé mentale, on s'interroge quant à la valeur de référence dans le champ de la psychanalyse prise par les fondements freudiens. Pour ce faire, les passages de l'œuvre dans lesquels l'auteur 


\section{SAÚDE MENTAL}

discute cette question sont mis en relief par le biais des écrits métapsychologiques, techniques ou ceux dans lesquels s'entremêlent des considérations autour des possibilités de la psychanalyse appliquée, incluant l'application à la thérapeutique en elle-même.

Mots clés: Freud, psychanalyse appliquée, fondement, thérapeutique

(La cuestión de la base en Freud: elementos para un psicoanálisis aplicado)

Entre las muchas reflexiones que suscita el debate acerca de la inserción del psicoanálisis y de los psicoanalistas en el dominio de la salud mental, en este trabajo se cuestiona el valor de orientar lo que Freud comprende acerca de la cuestión de los fundamentos del campo psicoanalítico. Con este objetivo se enfocan los pasajes en que el autor discute el asunto, sea en el ámbito de los escritos metapsicológicos, técnicos o en los que hace consideraciones acerca de las posibilidades de un psicoanálisis aplicado, incluyendo su aplicación a la terapéutica.

Palabras clave: Freud, psicoanálisis aplicado, fundamento, terapéutica

(Die Frage der Grundlage in Freud: Elemente der angewandten Psychoanalyse)

Unter den vielen Reflexionen, welche die Diskussion um den Einschluss der Psychoanalyse und der Psychoanalytiker in den Bereich der geistigen Gesundheit hervorrufen, wird hier der Orientierungswert von dem, was Freud unter grundlegende Fragen im Bereich der Psychoanalyse versteht, in Frage gestellt. Dazu werden die Textstellen betrachtet, in denen der Autor diese Frage diskutiert; sei es im Rahmen der metapsychologischen Schriften, der technischen Darlegungen oder der Textstellen, in denen er Überlegungen über die Möglichkeiten der in der Therapie angewandten Psychoanalyse anstellt.

Schlüsselwörter: Freud, angewandte Psychoanalyse, Grundlage, Therapeutik

Citação/Citation: Darriba, V. A. \& Silva, A. C. da. (2012, dezembro). A questão do fundamento em Freud: elementos para uma psicanálise aplicada. Revista Latinoamericana de Psicopatologia Fundamental, São Paulo, 15(4), 868-880.

Editor do artigo/Editor: Profa. Dra. Ana Cristina Costa Figueiredo

Recebido/Received: 7.11.2011 / 11.7.2011 Aceito/Accepted: 15.2.2012 / 2.15.2012

Copyright: (C) 2009 Associação Universitária de Pesquisa em Psicopatologia Fundamental/ University Association for Research in Fundamental Psychopathology. Este é um artigo de livre acesso, que permite uso irrestrito, distribuição e reprodução em qualquer meio, desde que o autor e a fonte sejam citados / This is an open-access article, which permits unrestricted use, distribution, and reproduction in any medium, provided the original author and source are credited.

Rev. Latinoam. Psicopat. Fund., São Paulo, v. 15, n. 4, p. 868-880, dezembro 2012 
Financiamento/Funding: Esta pesquisa é financiada pela Capes - Coordenação de Aperfeiçoamento de Pessoal de Nível Superior / This research is funded by Capes - Coordenação de Aperfeiçoamento de Pessoal de Nível Superior.

Conflito de interesses/Conflict of interest: Os autores declaram que não há conflito de interesses / The authors declare that has no conflict of interest.

\section{Vinicius AnCiães Darriba}

Professor do Programa de Pós-Graduação em Psicanálise da Universidade do Estado do Rio de Janeiro (Rio de Janeiro, SP, Br); Doutor em Teoria Psicanalítica pela Universidade Federal do Rio de Janeiro - UFRJ (Rio de Janeiro, RJ, Br).

Rua São Francisco Xavier, 524/10030 - bloco B - Maracanã

20550-011 Rio de janeiro, RJ, Br.

Fone: (21) 2334-7911

e-mail: vdarriba@centroin.com.br

\section{Angela Cristina da Silva}

Psicóloga; Mestranda em Psicologia na Linha de Psicologia Clínica do Mestrado em Psicologia da Universidade Federal do Paraná - UFPR; Participante do Laboratório de Psicanálise da mesma universidade.

Rua Atílio Bório, 139/202

80050-250 Curitiba, PR, Br

Fone: (41) 8859-3095

e-mail: angelacsilva@gmail.com 